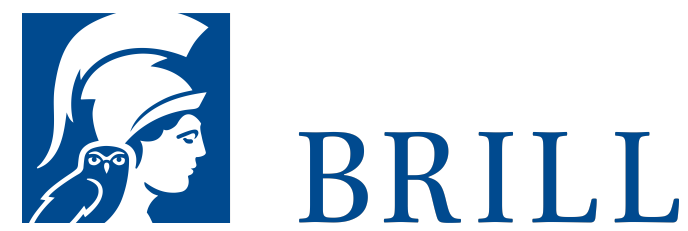

\title{
Degeneration erzählen
}

Literatur und Psychiatrie im Russland der 188oer und 189oer Jahre

Author: Riccardo Nicolosi

Riccardo Nicolosis Studie fördert ein neues, überraschendes Bild des russischen fin de siècle in seinen vielfältigen Beziehungen zum gesamteuropäischen Degenerationsdiskurs zutage. Während die literaturwissenschaftliche Forschung bislang lediglich die Verbindungen zwischen biomedizinischer Kunstkritik (vor allem Max Nordaus Entartung) und der russischen Literatur der décadence und des Symbolismus herausgestellt hat, zeigt Nicolosi das breite Panorama eines antimodernistischen Degenerationsdiskurses, der sich durch die engen Wechselwirkungen von Literatur und Psychiatrie konstituiert.

Die Studie fokussiert die narrative und rhetorische Verfasstheit der Entartung als Erzählmodell, das in Russland in Auseinandersetzung mit westeuropäischen Poetologien und Epistemologien entsteht, und zeichnet die mannigfaltigen Transformationen von Verfallserzählungen zwischen naturalistischer Poetik und psychiatrischen Fallgeschichten, Kriminalliteratur und Kriminalanthropologie, literarischem Darwinismus und Eugenik nach. Politisch konservative Psychiatrie und spätrealistische, naturalistische Literatur figurieren dabei als gleichberechtigte Akteure in einem Prozess der Gestaltung, Veränderung und Infragestellung von Degenerationsnarrativen. In dieser Perspektive offenbaren sich ungeahnte Verbindungen zwischen vergessenen und kanonischen Autoren der russischen Literatur: zwischen Dmitrij...

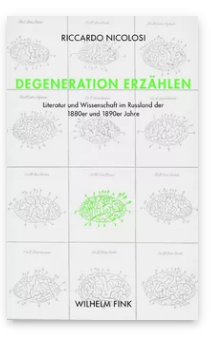

Pages: 410

Seiten

Language:

German

Subjects: Slavic, Literature and Cultural Studies Publisher: Brill| Fink

E-Book (PDF) Released online: 18 Dec 2017 ISBN: $978-3^{-}$ 8467-5307-1 List price Hardback Publication date: 15 Dec 2017 ISBN: $978-3^{-}$ 7705-5307-5 List price 
For more information see brill.com

Order information: Order online at brill.com +44330 333 0049 | customerservices@brill.com Submission information: brill.com/authors

Titles published by Brill | Fink, Brill | mentis or Brill | Schöningh: +49(o)715413279216| brill@brocom.de 